\section{O CICLISMO DE ESTRADA E A CONSTRUÇÃO DE UMA CULTURA NACIONALISTA: UM OLHAR SOBRE O TOUR DE FRANCE}

\author{
ROAD CYCLING AND NATIONALIST CULTURE CONSTRUCTION: LOOKING \\ INTO THE TOUR DE FRANCE
}

CICLISMO DE CARRETERA Y LA CONSTRUCCIÓN DE UNA CULTURA

NACIONALISTA: UNA MIRADA SOBRE EL TOUR DE FRANCE

Priscila Requião Lessa*, Marcelo Moraes e Silva*
Palavras chave:

Ciclismo de estrada.

Tour de France.

Nacionalismo.
Resumo: 0 presente ensaio busca analisar como uma construção histórica nacionalista contribuiu para a consolidação do maior evento do ciclismo de estrada do mundo: o Tour de France. Para alcançar tal intento foram analisadas fontes bibliográficas que versam sobre a construção histórica do evento e exploram a importância e o simbolismo do Tour de France na constituição da França moderna. A título de conclusão o ensaio aponta que essa competição, principalmente na primeira metade do século $\mathrm{XX}$, tornou-se uma celebração de uma cultura nacionalista francesa.

Abstract: This essay looks into how the nationalist historical construction contributes to the world's most important cycling competition: the Tour de France. It analyzed several bibliographic sources on the relationship between the Tour de France and modern France's constitution. By way of conclusion, it points out that the competition became a celebration of French nationalist culture, especially in the first half of the $20^{\text {th }}$ century.

Palabras clave: Ciclismo de carretera. Tour de France. Nacionalismo.
Resumen: Resumen: El presente ensayo busca analizar cómo una construcción histórica nacionalista contribuye para la consolidación del mayor evento de ciclismo de asfalto del mundo: el Tour de France. Para alcanzar ese objetivo se analizaron fuentes bibliográficas que se refieren a la construcción histórica del evento y analizan la importancia y el simbolismo del Tour de France en la constitución de la Francia moderna. Para concluir, el ensayo indica que esta competición, principalmente en la primera mitad del siglo XX, se transformó en una celebración de una cultura nacionalista francesa.
*Universidade Federal do Paraná. Curitiba, PR, Brasil. E-mail: pryslessa@gmail.com

Recebido em: 08-05-2016 Aprovado em: 08-12-2016

(c) (1) (8) Licence 


\section{INTRODUÇÃO}

Eles chegaram um por um, em ônibus-espaço-nave e reluzentes carros novos. Flutuaram sobre a grandeza fuliginosa de Liège, passando por pirâmides de alimentos e equipamento em armazéns e igrejas, através da penetrante névoa de cigarros, cerveja e frites. Passaram pela fervilhante brigada de formigas enchendo a cidade portátil com a barbearia, o banco, os toaletes portáteis com torneiras debruadas de ouro. Passaram pelas sedutoras curvas de ninfas-retrô das garotas de pódio do Credit Lyonnais, pelas caóticas hordas de caranguejos de 2.200 trabalhadores da imprensa. Passaram pelos garotos $S \& M$ vestidos de couro da brigada de motocicletas e pelos gendarmes de bigode retorcido que guardavam a entrada das áreas das equipes. Passaram pelos efervescentes bêbados belgas e pelas crianças belgas melancólicas e bem arrumadas. Passaram pela alucinação fantasiosa da procissão publicitária, com a xícara gigante e riquixá de salsicha e ratos motorizados e pelo leão de pelúcia com 60 metros de altura e pelo resto dos personagens do elenco de apoio do maior evento esportivo anual do mundo. Armstrong, Hamilton e Mayo passaram através de tudo isso, invisíveis, prontos, nervosos por causa do prólogo desse dia, o curto contra-relógio que dava 0 pontapé inicial ao Tour. - Lá vamos nós! - disse Armstrong ao sair do carro da equipe e se encaminhar para o ônibus. (COYLE, 2006, p. 229).

O Tour de France de 2004 começou com a euforia e com a expectativa característica de um dia do prólogo': quem seria o primeiro piloto a vestir a Camisa Amarela²? Contudo, foi pouco mais de um século antes, em 1903, que o primeiro Tour de France ganhou as estradas francesas e atraiu os olhares de milhares de espectadores sobre a maior corrida de bicicleta do mundo (DANCEY; HARE, 2012).

A profissionalização do ciclismo e sua consolidação como esporte competitivo teve origem na transição entre os séculos XIX e XX (HOBSBAWM, 1992). Weber (1988) salienta que nesse período, primeiramente, a bicicleta surgiu como um artefato inovador e associado aos valores de liberdade, urbanização e da valorização dos exercícios físicos. Weber (1988) e Vigarello (1997) argumentam que na França, especialmente, a prática do ciclismo rapidamente ganhou a admiração dos observadores que se aglomeravam nas beiras das estradas para verem os pilotos disputarem as corridas. Os autores indicam que a "invenção" do Tour de France, estimulada também pelos interesses comerciais das indústrias de bicicletas e dos jornais esportivos da época em busca de maior circulação, além de coroar o ciclismo de estrada com um evento grandioso, fomentou uma celebração cultural pelo território francês.

Tendo em vista a forte ligação do Tour de France com a história da França, este ensaio, inspirado nas contribuições do historiador francês Fernand Braudel (1989), tem como objeto central compreender como uma construção histórica nacionalista contribuiu para a consolidação do maior evento do ciclismo de estrada do mundo. O forte vínculo histórico do Tour com a cultura e com o nacionalismo francês está ligado ao período da Terceira República ${ }^{3}$ e a mutilação territorial nacional sofrida pelo país com a perda da Alsácia e Lorena, na guerra franco-prussiana de 1870.

Para sustentar a argumentação analisaram-se as seguintes fontes bibliográficas: Nicholson (1977), Weber (1988), Gaboriau (1996; 2003; 2012), Vigarello (1997), Perera e

1 Etapa de contrarrelógio individual ou por equipes, geralmente de curta distância, que geralmente abre o Tour de France, assim como o de diversas outras voltas ciclísticas.

2 A Camisa Amarela é usada para identificar o piloto que está liderando a corrida na soma de tempo de todas as etapas já disputadas. 
Gleyse (2005), Fumey (2006), Campos (2012), Dancey e Hare (2012) e Henry (2014). Tais obras foram selecionadas por serem aquelas que mais trabalham sobre a construção histórica do evento e exploram cada uma a sua maneira a importância e o simbolismo do Tour de France na constituição da França moderna.

\section{A BICICLETA E SUAS CORRIDAS NO CONTEXTO DA MODERNIDADE}

No contexto das modernas metrópoles europeias do final do século XIX, surge um novo estilo de vida que valorizava a prática de exercícios físicos. Embora muitas cidades ainda conservassem seus laços com a vida rural, os principais centros urbanos começaram a se inserir num projeto moderno, realizando um reordenamento mais racional dos seus espaços. As grandes obras, realizadas em Paris sob o comando do Barão de Haussman, reordenaram a capital francesa e inspiraram outras cidades a seguirem seu exemplo. A reordenação dos espaços veio acompanhada da reorganização dos olhares sobre a cidade, que culminaram com outros modos de se comportar. Entre essas novas formas de vida se encontravam as que valorizavam um discurso da cultura física (VIGARELLO, 1978).

A introdução de um ideário da cultura física no estilo de vida das principais cidades europeias não assumiu um caráter esportivo e competitivo em seus primeiros momentos. Esse foi um processo que se deu posteriormente, de forma gradativa, à medida que os exercícios físicos passaram a tomar um viés competitivo. No início, tais atividades surgiram como um novo valor, um diferente estilo de vida, especialmente entre os mais abastados que dispunham de tempo para praticá-las (VIGARELLO, 1978; HOBSBAWM, 1992; BAKER, 2004).

Segundo aponta Baker (2004), foi na Inglaterra que algumas dessas práticas assumiram uma forma mais regrada, e posteriormente culminariam na invenção do esporte moderno. Vigarello (1978) lembra que em todo território europeu, no final do século XIX e início do XX, várias atividades esportivas ganharam prestígio nas suas principais cidades. Muitas agremiações e clubes esportivos foram criados. Nas escolas havia um empenho em introduzir o esporte como forma disciplinadora. Foi nessa ambiência que as bicicletas passaram a ser um elemento muito presente nas principais cidades europeias.

Segundo Weber (1988), desde sua origem no final do século XIX, a bicicleta simbolizou o progresso. Gaboriau (2003) indica que a bicicleta, por romper distâncias, fascinava os indivíduos, sendo vista então como uma máquina lúdica, ligada a liberdade e a velocidade. 0 novo artefato fora, no início, comparado por muitos aos cavalos. Primeiro porque deixou de ser um artigo de luxo e ganhou as camadas mais populares, passando a ser vista como um meio de locomoção mais acessível que o equino. Depois, porque os fabricantes de bicicletas passaram a disputar espaço nesse mercado emergente. Sendo assim, as primeiras corridas competitivas, em velódromos especialmente construídos, foram o modo de apresentação das novidades que a cada dia surgiam e se voltavam para um público jovem e não tão abastado como os das corridas de cavalo. Conforme aponta Weber (1988, p. 241): "[...] as corridas de bicicleta eram o primeiro esporte popular dos tempos modernos e o primeiro a oferecer a inúmeros profissionais uma via de promoção econômica, portanto social". Gaboriau (1996) salienta que, apesar de no início do século XX a bicicleta ser ainda um artefato burguês, ela se tornou um objeto mais acessível às classes menos favorecidas economicamente. 
A bicicleta foi estimada como uma invenção francesa: ela foi o primeiro meio de transporte realmente popular e barato. Era feita e utilizada por trabalhadores que estavam se deslocando para as cidades e para além dos ofícios tradicionais. Mesmo que ainda mantivessem vínculos com suas antigas atividades. [...] As corridas de bicicletas foram um dos primeiros esportes populares: inicialmente envolvia competidores entre os trabalhadores e não entre os profissionais, porque eles podiam empurrar 20 quilos de metal pelas estradas em más condições durante dias e noite e carregando consigo suas origens humildes, assim como as dos espectadores que os viam passar. [...] (CAMPOS, 2012, p. 22-61, 2012 Tradução livre).

À medida que 0 andar de bicicleta se popularizava, começou também a ocorrer 0 surgimento do ciclismo como uma prática competitiva. Tal fato contribuiu para o surgimento dos primeiros clubes, que na virada do século XIX para o XX já contavam com membros de condições sociais menos abastadas. Eram balconistas, artesãos, operários (WEBER, 1988; HOBSBAWM, 1992; CAMPOS, 2012). Weber (1988) lembra que outro fator que determinou 0 fortalecimento do ciclismo foi o interesse dos fabricantes de bicicletas, pois a competitividade destes pelos mercados consumidores levou-os a sistematizarem as primeiras corridas. As primeiras competições ganharam expressão maior nas estradas francesas, influenciando 0 futuro desse esporte, com competições cada vez mais longas e de percursos cada vez mais difíceis, conforme lembram Perera e Gleyse (2005).

Nesse sentido, o Tour de France, considerado a maior competição ciclística do mundo, surgiu nesse contexto competitivo tanto para os fabricantes de bicicleta como para os competidores. Afinal, cada vez mais indivíduos se interessavam pelas suas corridas. 0 ciclismo de estrada deixava de ser, conforme apontam Weber (1988), Gaboriau (1996) e Campos (2012), uma atividade elitizada e possibilitava a inúmeros ciclistas profissionais uma possibilidade de ascensão econômica e de rompimento de determinadas fronteiras relacionadas à classe social.

Weber (1988) ainda salienta sobre a importante relação entre o ciclismo e a comercialização esportiva no alvorecer do século XX. As corridas de bicicleta pelas estradas da França passaram a promover marcas, e com isso surgiram diversas formas de anúncios publicitários. Isso estendeu a prática da modalidade a muitos indivíduos que, por sua vez, influenciaram inúmeros outros, ajudando significativamente na popularização das corridas de bicicleta por todo território europeu. Nesse contexto, o Tour de France foi de fundamental importância para a consolidação do ciclismo de estrada como uma modalidade esportiva.

\section{A INVENÇÃO DO TOUR DE FRANCE: A CONSTRUÇÃO DE UM NACIONALISMO FRANCÊS}

Para coroar o ciclismo de estrada como um evento "grandioso" e "sem precedentes", ele foi promovido como uma corrida pela França "de Paris às ondas azuis do Mediterrâneo" (WEBER, 1988). Perera e Gleyse (2005) salientam que as distâncias na época do primeiro Tour de France, em 1903, já eram consideradas além da capacidade humana, transformando seus participantes em verdadeiros heróis. Ainda mais num momento histórico em que as condições das estradas, os conhecimentos sobre treinamento, nutrição e a tecnologia para a fabricação das bicicletas eram enormes desafios a serem superados. 
De acordo com Weber (1988), o primeiro Tour de France aconteceu em 1903, num percurso de 2400 quilômetros percorridos em 19 dias, e, embora a edição 1904 tivesse muitas críticas pelo seu apelo comercial, a corrida tornou-se ao longo dos anos seguintes o maior evento do ciclismo mundial:

Onde o Tour se detinha à noite, ou mesmo em paradas ou barreiras de fiscalização, feiras improvisadas apareciam: iluminações, corridas locais de bicicletas, outras competições, lutas de boxe, danças públicas, concertos, orquestras. 0 prefeito e o conselho municipal vinham saudar os corredores, fazer brindes e discursos em sua homenagem. Logo as estradas começaram a ser desimpedidas e fechadas ao tráfego, o transporte público interrompido, crianças liberadas mais cedo das escolas. Como o inventor do Tour Géo Lefèvre, escreveu em 1906: 'o Tour é, a partir de agora, o poderoso tantã anual que, durante um mês inteiro desperta toda uma nação para o ciclismo [...] o prodigioso desfile popularizador do esporte (WEBBER, 1988, p. 257).

De acordo com Gaboriau (2012), o Tour de France simbolizou uma ruptura, pois era o fim da era de ouro da bicicleta nos meios sociais mais abastados, agora dedicados aos artefatos motorizados e às corridas de carro. 0 autor lembra que os preços das bicicletas foram diminuindo e as classes populares foram apropriando-se do espaço competitivo do ciclismo. Além dessas questões, o Tour, até meados do século XX, representou muito mais que uma corrida de bicicleta. A competição incorporou-se à história cultural da França, ressaltando seus heróis, mitos, glórias e dores dentro das diversas paisagens do território francês (WEBER, 1988; HENRY, 2014).

Thiesse (1995) e Fumey (2006) salientam que a história da França sustenta uma forte lembrança do período da "Terceira República". A guerra franco-prussiana deixou como herança para os franceses o que eles próprios lembram como uma mutilação do seu território nacional, com a perda para os alemães das regiões da Alsácia e da Lorena. Assim, Henry (2014) afirma que em um contexto de sentimento nacionalista e patriótico que se espalhava por toda a Europa do final do século XIX, o Tour assumiu o papel de redesenhar, pela sua rota, as fronteiras e as paisagens da França. Segundo Weber (1988), o percurso representava uma parte da memória francesa. Era uma exaltação do seu território, justamente num contexto instável no qual passava a Terceira República Francesa4.

A importância do Tour de France como uma celebração nacionalista e territorial pode ser observada em algumas etapas do evento. 0 itinerário da corrida contempla territórios historicamente importantes para a França, com forte relação com as guerras travadas pelo país ao longo de sua história. Vigarello (1997) argumenta que o evento foi criado à imagem de outros passeios tradicionais pelo território francês, realizados por jornaleiros, soberanos e/ou ainda por crianças em idade escolar. Segundo o autor, a rota do evento transformou a paisagem da França em pano de fundo para o espetáculo esportivo e ainda resgatou uma memória nacional ligada aos personagens clássicos de Joana D’Arc e Napoleão: "O caminho do Tour de France é um símbolo do patrimônio nacional e a história da criação do Tour e das suas rotas são tão importante quanto à história da corrida em si" (VIGARELLO, 1997, p. 469470- Tradução livre).

\footnotetext{
4 Somam-se de forma valorosa ao comportamento orgulhosamente nacionalista elementos como etnicidade, território e a construção da língua nacional, pois desde o final do século XVIII diversas nações retomaram línguas vernáculas ligadas aos seus campesinatos, suscitando com isso um resgate folclórico de suas populações. Sobre os nacionalismos nos séculos XVIII, XIX e início do século XX consultar o livro de Hobsbawm (1990) e o texto de Thiesse (1995).
} 


\section{A EXPERIÊNCIA DO TOURE A GRANDIOSIDADE FRANCESA}

Todos os anos equipes ranqueadas e cerca de duzentos corredores são contratados para competir. Todos os anos há uma viagem pelas aldeias de cerca de 4 mil pessoas e mil veículos, seguindo o caminho do Tour de France por três semanas do verão francês. Todos os anos milhares de espectadores alinham-se em frente as suas casas ou fazem uma peregrinação aos pontos principais da rota do Tour para verem o pelotão e seus dirigentes passarem. Todos os anos o Tour é relatado em detalhes cada vez maiores pelo rádio, televisão, imprensa escrita e internet. Financeira e comercialmente o Tour envolve quantidades significativas em dinheiro e grandes premiações para os seus pilotos, numa soma que supera 2,5 milhões de dólares. Qualitativamente, o Tour de France, depois de um século, continua sendo indiscutivelmente a maior prova de ciclismo do mundo (DANCEY; HARE, 2012, p. 2-3, p. 66 - Tradução livre).

A incrivel jornada do Tour de France no início do século XX foi iniciada por Henri Desgrange (WEBER, 1988; AUGENDRE, 2009). Naquela época, na França, as corridas de bicicleta já haviam se popularizado em velódromos e nas estradas com corridas de longas distâncias. Como dito anteriormente, o cenário do surgimento do ciclismo europeu foi fomentado pela grande disputa entre fabricantes de bicicletas. Além disso, a imprensa escrita estava interessada em aumentar a circulação de seus jornais. Segundo Weber (1988), a invenção do Tour exemplifica esse contexto, pois o evento surgiu da vontade de Desgrange, diretor do jornal $L^{\prime} A u t 0^{5}$, um entusiasta do ciclismo, que a partir de uma ideia de seu funcionário Geo Lefrèvre, motivado pela disputa comercial com o grande rival, o periódico Vélo, sistematiza a ideia do evento.

$\mathrm{Na}$ batalha pelo aumento de circulação o L'Auto pretendia atrair leitores com matérias sensacionais sobre ciclismo de estrada. Essas corridas já existiam na França, conforme lembra Weber (1988), desde o final do século XIX, como, por exemplo, a Paris-Brest-Paris ${ }^{6}$. Contudo, algo ainda mais "grandioso" precisava ser criado. Uma corrida que abraçasse todo o território francês, como na viagem do conto escolar "Le Tour de France par deux enfants", que foi para o Tour de France uma grande inspiração. Em 1903, a ideia finalmente se concretizou:

[...] Mas ele mudou de idéia no dia seguinte e convocou o chefe da categoria de corridas:

Eu estive pensando. Sua proposta é interessante. Mas se nós gerenciássemos este evento em conjunto, ele não será chamado de Jornada de Seis Dias na Estrada.

- Então, como os chamaríamos?

- 0 Tour de France (AUGENDRE, 2009, p. 18 - Tradução livre).

Desde sua criação o evento foi marcado pelos grandes desafios impostos. Os atletas eram, a cada edição, incentivados à superação. A jornada solitária - como era no princípio dos competidores pelas longínquas estradas francesas transmitia aos espectadores, desde suas primeiras edições, uma qualidade épica inovadora. Nas palavras de Nicholson (1977, p.

5 O Jornal L'Auto é o antecessor do atual L'Equipe, jornal esportivo francês com ampla cobertura em futebol, automobilismo e ciclismo. O seu nome já indicava o grande entusiasmo por corridas na França (WEBER, 1988).

6 A Paris-Brest-Paris era uma corrida de bicicleta de longa distância, que teve sua primeira edição em 1891, em um percurso de 1.200 quilômetros, entre as cidades de Paris e Brest, com retorno à capital francesa (WEBER, 1988).

70 livro publicado em 1877 por Agostinho Fouillée, sob o pseudônimo de G. de Bruno, foi amplamente utilizado nas escolas francesas da Terceira República. O livro narra as aventuras de duas crianças pelas diversas províncias da França em busca de sua família após a morte de seu pai. Tudo acontece no contexto da perda dos territórios da Alsácia e Lorena depois da guerra franco-prussiana. A viagem dos jovens é uma exploração geográfica, histórica e cultural da França, e um convite ao nacionalismo e ao patriotismo francês (THIESSE, 1995; OZOUF; OZOUF, 1997). 
53), o Tour de France "[...] transformava os ciclistas em campeões, e os campeões em heróis". O caráter épico desde seus primeiros anos de história edificou a condição do evento. 0 Tour, além de uma corrida de bicicleta, tinha na sua constituição todo o projeto da modernidade e através de sua rota revelava mais da França aos franceses, conforme aponta Campos (2012, p. 34 - Tradução livre):

No entanto, a retórica oficial em torno do evento sempre enfatizou, como Michelet, o fato de que ela abrange toda a variedade e a beleza da França. Em 1938, Henri Desgrange, seu idealizador em 1902, agora Diretor tanto de L'Auto como do evento, e o 'grande homem velho' do Tour, leu esta declaração lírica para o rádio: 'Há outro aspecto da corrida que me interessa tanto como o esporte, que é a rota do Tour, que entrecruza todas as belas províncias do nosso país, e me dá emoção considerável a cada ano. Tenho orgulho de ser um francês que adora seu país e é sensivel às emoções que surgem das belas paisagens, desde os vários costumes e práticas dos nossos diferentes departamentos. Tenho sido e ainda estou tocado a cada ano por diversos pontos turísticos do país encontrados. Pode ser um produtor de vinho, pode ser um lenhador nas florestas ao sul de Bordeaux, pode ser um pastor, pode ser uma paisagem verde e fértil ou pode ser uma paisagem seca no sul. Todos os anos, eu olho para a frente com grande prazer, e com paixão, para as emoções que se reúnem ao longo do caminho'.

Até os dias atuais o Tour conserva essa característica épica que os franceses admiram quando os pilotos, reunidos no grande pelotão, passam por suas diversas cidades, vilas e/ou campos. Os preparativos são muitos à espera do momento em que os corredores apontarão de longe vencendo a estrada em sua direção para ganharem as ruas dos lugarejos por onde passam. As ruas estreitas das pequenas cidades nas quais passa o pelotão abrigam os moradores que aguardam ansiosos o momento de verem os pilotos de perto. As populações locais começam a aglomerar-se também em torno da praça, sentados nos gramados. Aos poucos a longa espera toma ares de comunhão, os indivíduos passam a dividir os espaços, às vezes apertados, com 0 olhar sempre muito atento na estrada. A corrida é uma celebração entre os franceses. Um festejo não somente do esporte, do ciclismo, mas também uma comemoração de toda a França e de todos os franceses, pois, conforme apontam Dauncey e Hare (2012), o Tour é uma simbologia que transcende o ciclismo e se apropria de conceitos como patriotismo e nacionalismo.

\section{TERMO TOUR DE FRANCE: A AFIRMAÇÃO DO NACIONALISMO FRANCÊS}

Campos (2012) salienta que o termo Tour de France para denominar a corrida é providencial. A terminologia traz a simbologia de um evento que celebra o território francês. 0 nome que na contemporaneidade teve um significado de passeio turístico remete às lembranças mais antigas sobre esse país. 0 autor lembra ainda que o termo pode ter tido sua origem no século XVI e foi resgatado em um momento de necessidade de consolidação territorial da França, decorrente da instabilidade geopolítica da Terceira República e da inaceitável perda dos territórios da Alsácia e Lorena. Vigarello (1997) e Campos (2012) argumentam que a palavra tour tem um significado de turnê reforçando o conceito de união territorial, porque está historicamente ligada às excursões pelo reino, ou seja, às visitas feitas pelo monarca em seus domínios, mapeando com isso quais eram realmente os vassalos leais.

Nesse sentido, o significado do termo tour é interpretado por Campos (2012) como de caráter político, ligado, desde Charles $I X^{8}$, à necessidade de inspeção territorial, e que a 
partir do início do século XX sustentou a ideia de demarcação do território. Significativamente o termo tour tem raízes nacionalistas desde Jules Michelet, o historiador dos séculos XVIII/XIX que era um nacionalista por paixão, que teve no amor pela França sua grande religião. Em sua obra Tableau de La France, Michelet escreve sobre uma viagem pela França que inicia e termina em Paris. Neste livro descreve as províncias francesas e recupera diversas histórias como, por exemplo, a de Joana D'Arc.

Como pode ser visto, o termo no século XIX estava ligado à consolidação do território e da construção de um nacionalismo francês. Histórias de reinos e reis, do povo e da geografia da França são elementos do patriotismo francês em superação à mutilação de seu território ocorrido em 1870. Fumey (2006) lembra que uma Volta à França de bicicleta resgatava 0 sentimento de união e de consolidação do território nacional, em que certas passagens representavam glórias passadas como a do bicentenário da Revolução Francesa quando 0 pelotão passou entre Versalhes e os Campos Elísios e as Tuileries. Nesse sentido, o Tour, conforme apontam Dauncey e Hare (2012), é a representação da França como nação, porque reconta a história deste país através da sua rota, explorando seu patrimônio histórico, arquitetura e beleza naturais.

Campos (2012) ainda salienta que é possível relacionar o significado do termo com a religião, no sentido da peregrinação por um território sagrado. Le Goff (1983) indica que a peregrinação ganhou importância como prática religiosa na França durante a Idade Média. $\mathrm{Na}$ opinião do historiador as andanças pelo território francês tinham inúmeros significados. Poderia ser por reforço da fé, abandono da vida material e até mesmo uma forma de penitência. Le Goff lembra que em termos territoriais o próprio conceito de nação (que tomará forma na Europa somente depois do século XIV) se relaciona com o termo de Cristandade. A partir do Ano Mil a expansão da Cristandade avançou em terras desconhecidas no Oriente Médio e em direção à Península lbérica, reconquistando territórios dominados por não cristãos e anexando domínios ao que historiador francês chamou de "Respublica Christiana".

O Tour é edificado então como um passeio sobre o território francês que resgata os antepassados e reivindica os territórios desta nação (VIGARELLO, 1997; CAMPOS, 2012). A corrida de bicicletas desde sua "invenção" esteve ligada a valores simbólicos da demarcação das fronteiras francesas ${ }^{9}$, reforçando 0 entendimento de comunidade que compartilha 0 sustento. Através de uma mesma paisagem os franceses podem todos os anos celebrar seu território, pois é na passagem do pelotão de ciclistas que uma ideologia nacional é valorizada, principalmente após a guerra de 1870.

Como isto a França, a partir da Terceira República, caminhou para o alargamento dos costumes locais em busca da criação de um nacionalismo (BRAUDEL, 1989; THIESSE, 1995). Para isso fez uso da sua fronteira para a união territorial e a construção da ideia de nação. O Tour de France deveria, nesse contexto, unir as cidades do país e com isso celebrar este território. As primeiras edições do Tourpartiam dos subúrbios de Paris, porque lá era o ponto de partida da vida na França. No seu centenário em 2003, diversos simbolismos nacionalistas foram resgatados:

O Tour de 2003 fará sua partida inicial nos subúrbios de Paris do famoso café Reveil-Matin em Montgeron no mesmo percurso original que partiu em 1 de Julho

entre os anos de 1560 a 1574, realizava inúmeras viagens de inspeção por todo o território de seu reino.

9 Segundo Campos (2012), a rota do Tour fora traçada assemelhando-se a um polígono unindo as fronteiras e as fechando em um hexágono. Esse conceito era importante especialmente nas zonas montanhosas fronteiriças dos Pirineus e dos Alpes. A ideia do hexágono é abandonada na rota do evento somente depois da Segunda Guerra Mundial, quando o nacionalismo enfraquece em toda a Europa. 
de 1903. No entanto, haverá também um desvio para passar na frente do mais novo e o mais prestigioso monumento do esporte na França: o Stade de France, em Saint-Denis, associado com a famosa vitória do futebol na Copa do Mundo da França em 1998 (...) As principais cidades que acolheram o Tour em 1903 também irão hospedá-lo em 2003: Lyon, Marselha, Toulouse, Bordeaux, Nantes, não mais como zonas urbanas isoladas e centros industriais da virada do século XIX que representavam o futuro da transformação da França do atraso rural e agrícola, mas como modernas e industrializadas conurbações multiétnicas abertas aos eixos do transporte europeu. A rota incluirá os Alpes e etapas de montanha dos Pirineus, que vieram a simbolizar os esforços sobre-humanos impostos aos seus pilotos: le Galibier, l'Alpe d'Huez, l'zoard, le Tourmalet, Luz-Ardiden. No Tour de 1953 (o quadragésimo a ser executado), o aniversário de 50 anos da corrida foi uma celebração consideravelmente menor, ao passo que, partindo da rota 1903, 0 Tour 2003 irá fazer desvios para comemorar seus fundadores Géo Lefèvre, Henri Desgrange e Jacques Goddet. (DAUNCEY; HARE, 2012, p. 12-13 - Tradução livre).

$\mathrm{Na}$ edição centenária a intenção era promover um evento grandioso e heroico para descrever a geografia e a história da nação, como um apelo à sua memória nacionalista. Os pilotos largaram o prólogo, aos pés da Torre Eiffel, correndo ao longo do rio Sena e chegando a La Maison de la Radio. Como de costume, a multidão se aglomerava atrás das grades de proteção cobertas pelos cartazes dos patrocinadores. Do alto da Torre Eiffel havia também uma aglomeração de curiosos e admiradores que deram uma pausa em seu passeio para celebrar a passagem dos pilotos. No dia seguinte, no mesmo horário que em 1903, foi dada a largada da primeira etapa do Tour de France do centenário nos subúrbios de Paris. Nesse ano, conforme apontam Dauncey e Hare (2012), resgatou-se todo o simbolismo do primeiro Tour de France. Campos (2012) argumenta que ao fim da batalha, depois das vinte e uma etapas cumpridas, os pilotos retornavam a Paris e, como prêmio, em frente ao Arco do Triunfo, atravessaram a Champs Elysées, em uma corrida final, que misticamente simboliza o "The Elysian Fields", termo pré-cristão para designar o paraíso.

Outro ponto que merece ser salientado é a expansão do Tour para além do território francês. Campos (2012) lembra que, a partir de 1960, o evento teve algumas de suas edições iniciadas em outros países europeus, como Irlanda, Inglaterra e Holanda. $O$ autor lembra que, num contexto do pós-guerra, a partida dos pilotos além das fronteiras da França resgatou mais uma vez o simbolismo heroico da sua história territorial. Representou no imaginário dos franceses uma luta épica travada no território adversário. Os filhos da França atravessam além de suas fronteiras para iniciarem uma batalha. Quando o pelotão entra em território francês é a representação dos filhos de volta ao seio da sua mãe. As marcas históricas das guerras estão muito presentes na história do Tour de France. Os sentimentos que afloram desde a guerra de 1870 permitem entender as aproximações simbólicas que se construíram em torno do evento. A entrada do pelotão em Paris, depois das etapas iniciais em território estrangeiro e a cuidadosa construção das suas rotas dentro do território francês são exemplos dessa formulação simbólica.

Nesses anos anteriores à guerra patriótica, os corredores são frequentemente descritos como 'soldados del desporte', 'tropa de elite', 'sagrado batalhão', e deles se diz que pode-se oferecer uma 'saudável lição de energia' para a juventude francesa (GABORIAU, 2003, p. 150 - Tradução livre).

Para Campos (2012), a passagem do pelotão como uma representação heroica ligada à guerra é tão significativa que 0 autor compara a presença de moças entusiasmadas 
à beira das estradas acenando ao pelotão e/ou nas cidades aguardando sua chegada com a presença de mulheres recepcionando os soldados franceses que voltavam da guerra depois de 1944. A presença feminina em ambas as situações representa a recompensa ao guerreiro. Praticamente um espólio de guerra ${ }^{10}$.

Um exemplo do nacionalismo no Tour pode ser visto na edição de 1947, o primeiro do pós-guerra. $\mathrm{O}$ evento trouxe à tona aos franceses o heroísmo de seus soldados, ainda num período em que a guerra estava latente, quando os ciclistas exaustos e sujos cruzam a linha de chegada aguardada pela multidão. Para completar a glória francesa, em 1947 o Tour teve um vencedor francês: Jean Robic (DAUNCEY; HARE, 2012).

A partir da década de 1950 o Tour internacionalizou-se e perdeu um pouco da sua característica nacionalista, visto que o próprio nacionalismo construído nas bases ideológicas do século XIX começou a se enfraquecer em toda a Europa. Pilotos estrangeiros chegavam e passaram a ser bem recebidos. 0 evento não era mais o palco de disputas heroicas que os franceses utilizavam para destacar a bravura dos seus filhos. Em suas últimas edições, os atletas passam a vir de todas as partes do mundo: latinos, germânicos, belgas, norteamericanos e, mais recentemente, o pelotão tem se composto também por pilotos asiáticos e africanos.

\section{CONSIDERAÇÕES FINAIS}

O surgimento da bicicleta no contexto da modernidade simbolizou o progresso e estimulou a formação de novos valores ligados à prática esportiva e à vida urbana. No início do século XX, o andar de bicicleta se popularizou. A invenção do Tour de France, relacionado aos interesses comerciais dos fabricantes de bicicletas e da imprensa escrita, estabeleceu desde sua origem um forte vínculo que ia muito além do esporte.

Os nacionalismos, característicos das primeiras décadas do século XX, mostraram-se presentes no Tour através da sua rota pelas estradas da França. As lembranças da guerra franco-prussiana, que resultou em parte na perda dos territórios franceses da Alsácia e Lorena, colaboraram para fortalecer o sentimento nacionalista presente no evento.

A história cultural da França tem um significado determinante na história do Tour de France. A rota da competição passou a representar, em parte, uma memória francesa. 0 pelotão avançava por regiões de antigas batalhas e/ou por localidades de onde personagens famosos de sua história tinham origem. $\mathrm{O}$ evento simbolizou uma possibilidade de resgate da história cultural francesa, pela celebração de seu território e pela presença dos corredores franceses na disputa.

Com o enfraquecimento do nacionalismo depois da Segunda Guerra Mundial, o Tour de France transformou-se em um evento mais internacionalizado. Entretanto, conserva, até hoje, elementos relacionados ao orgulho nacional francês e à celebração do seu território. Tal característica pode ser percebida pela forte presença das populações locais e pela preparação

10 A organização do Tour de France ainda não vê uma possibilidade real da prova se estender às mulheres com o mesmo formato feito para os homens. Embora se fale da existência de um Tour de France feminino, o evento não conta com o mesmo prestígio e nem com o mesmo simbolismo da corrida masculina. Até o nome, por questões de direitos comerciais, não é o mesmo e chama-se Route de France Féminine Internationale. Esta volta feminina também é feita em edições por etapas, em número bem menor que no evento masculino (SANSON, 2016). Sendo assim, como aponta Terret (2003), os mais cem anos de história do Tour de France são exclusivamente masculinos, sendo uma celebração da masculinidade hegemônica. Nesse sentido, é possível afirmar que o nacionalismo que esse evento concretiza está relacionado com aspectos desta masculinidade. 
dos detalhes decorativos que enfeitam as localidades por onde passa o pelotão. Todos os anos, pelos caminhos do Tour os franceses se preparam para receber os pilotos e as caravanas, e o fazem cada vez mais acompanhados por indivíduos de muitos lugares do mundo, fazendo do Tour um dos maiores eventos esportivos da atualidade.

\section{REFERÊNCIAS}

AUGENDRE, Jacques. Le tour: 25 étapes de legende. Paris: Solar, 2009.

BAKER, Norman. Whose hegemony? The origins of the amateur ethos in nineteenth century English Society. Sport in History, v. 24, n. 1, p. 1-16, 2004.

BRAUDEL, Fernand. A identidade da França: o espaço e a história. São Paulo: Globo, 1989.

BOUTIER, Jean; DEWERPE, Alain; NORDMAN, Daniel. Un Tour de France royal: le voyage de Charles IX (1564-1566). Paris: Aubier, 1984.

CAMPOS, Christopher. Beating the Bounds: The Tour de France and national identity. In: DAUNCEY, Hugh; HARE, Geoff. The Tour de France 1903-2003: a century of sporting structures, meanings and values (Sport in the Global Society). New York: Routledge, 2012. p. 1-67.

COYLE, Daniel. A luta de Lance Armstrong: a luta de um homem contra o destino, a fama, o amor, a morte, o escândalo e alguns outros rivais a caminho do Tour de France. São Paulo: Gaia, 2006.

DAUNCEY, Hugh; HARE, Geoff. The Tour de France: A Pre-Modern contest in a Post-Modern contest. In: DAUNCEY, Hugh; HARE, Geoff. The Tour de France 1903-2003: a century of sporting structures, meanings and values (Sport in the Global Society). New York: Routledge, 2012. p. 1-32.

FUMEY, Gilles. Le Tour de France ou le vélo géographique. Annales de Géographie, v. 4, n. 650, p. 388-408, 2006.

GABORIAU, Philippe. Le Tour de France et le vélo: histoire sociale d'une épopée contemporaine. Vingtième Siècle. Revue d'Histoire, v. 50, n. 1, p. 162, 1996.

GABORIAU, Philippe. El Tour de Francia y la belle epoque del ciclismo. Revista Sociedad y Economia, n. 4, p. 137-158, 2003.

GABORIAU, Phillipe. The Tour de France and cycling's belle époque. In: DAUNCEY, Hugh; HARE, Geoff. The Tour de France 1903-2003: a century of sporting structures, meanings and values (Sport in the Global Society). New York: Routledge, 2012. p. 1-52.

HENRY, Christelle. La belle époque du vélo finistérien. Lille: The Book, 2014.

HOBSBAWM, Eric John. Nações e nacionalismo desde 1870: programa, mito e realidade. Rio de Janeiro: Paz e Terra, 1990.

HOBSBAWM, Eric John. A era dos Impérios 1875-1914. Rio de Janeiro: Paz e Terra, 1992.

LE GOFF, Jacques. A civilização do ocidente medieval. Lisboa: Estamapa, 1983.

NICHOLSON, Geoffrey. The great bike race. London: Hodder and Stoughton, 1977. 
OZOUF, Jacques; OZOUF, Mona. Le petit livre rouge de la République. In: NORA, P. (Dir.). Les lieux de mémoire. Paris: Gallimard, 1997. v. 1, p. 291-321.

PERERA, Eric; GLEYSE, Jacques. O doping ao longo do século XX na França: representações do puro, do impuro e do segredo. Revista Brasileira de Ciências do Esporte, v. 27, n. 1, p. 55-74, 2005.

SANSON, Nicole. Cyclisme/La Route de France féminine: Saint-Quentin va donner le top départ de cette course référence. Aisne Nouvelle. 5 ago. 2016. Sport Région. Disponível em: <http://www. aisnenouvelle.fr/sport-region/cyclismela-route-de-france-feminine-saint-quentin-va-ia0b0n402646>. Acesso em: 10 set. 2016.

TERRET, Thierry. Le Tour, les hommes et les femmes. Essai sur la visibilité masculine et l'invisibilité féminine. In: PORTE, Patrick. VILA, Dominique (Eds.). Maillot jaune: regards croisés sur le centenaire du Tour de France. Biarritz: Atlantica, 2003. p. 211-238.

THIESSE, Anne-Marie. La petite patrie enclose dans la grande: regionalismo e identidade nacional na França durante a Terceira República (1870-1940). Revista Estudos Históricos, v. 8, n. 15, p. 3-16, 1995.

WEBER, Eugen Joseph J. França fin-de-siècle. São Paulo: Companhia das Letras, 1988.

VIGARELLO, Georges. Le corps redressé: histoire d'un pouvoir pédagogique. Paris: Delarge, 1978.

VIGARELLO, Georges. Le Tour de France. In: NORA, Pierre. (Ed.). Les Lieux de mémoire, Paris:

Gallimard, 1997. v. 2, p. 885-925.

\section{Agradecimentos:}

Agradecemos aos dois avaliadores anônimos da revista Movimento, visto que suas análises contribuíram significativamente para o aprofundamento teórico do ensaio apresentado. 